Article

\title{
Virtual Globes: Serving Science and Society
}

\section{Thomas Blaschke $^{1,2, *}$, Karl Donert ${ }^{3}$, Frank Gossette ${ }^{4}$, Stefan Kienberger ${ }^{1}$, Martin Marani ${ }^{5}$, Salman Qureshi ${ }^{2,6}$ and Dirk Tiede ${ }^{1}$}

1 Centre for Geoinformatics, University of Salzburg, Hellbrunnerstrasse 34, Salzburg 5020, Austria; E-Mails: stefan.kienberger@sbg.ac.at (S.K.); dirk.tiede@sbg.ac.at (D.T.)

2 Department of Geography and Geology, University of Salzburg, Hellbrunnerstrasse 34, Salzburg 5020, Austria; E-Mail: salmanqureshi@uok.edu.pk

3 European Association of Geographers, 19 Blackwood Avenue, Liverpool L25 4RN, UK;

E-Mail: kdonert@yahoo.com

4 Department of Geography, California State University, 1250 Bellflower Blvd, Long Beach, CA 90840, USA; E-Mail: gossette@csulb.edu

5 Department of Geography and Environmental Studies, University of Nairobi, Postbox 30197, Nairobi 00100, Kenya; E-Mail: martinmarani@yahoo.co.uk

6 Department of Geography, Humboldt University, Berlin, Rudower Chaussee 16, Berlin 12489, Germany

* Author to whom correspondence should be addressed; E-Mail: thomas.blaschke@sbg.ac.at; Tel.: +43-(0)662-8044-5225; Fax: +43-(0)662-8044-525.

Received: 30 June 2012; in revised form: 10 August 2012 / Accepted: 13 August 2012 / Published: 31 August 2012

\begin{abstract}
Virtual Globes reached the mass market in 2005. They created multi-million dollar businesses in a very short time by providing novel ways to explore data geographically. We use the term "Virtual Globes" as the common denominator for technologies offering capabilities to annotate, edit and publish geographic information to a world-wide audience and to visualize information provided by the public and private sectors, as well as by citizens who volunteer new data. Unfortunately, but not surprising for a new trend or paradigm, overlapping terms such as "Virtual Globes”, "Digital Earth", "Geospatial Web”, “Geoportal” or software specific terms are used heterogeneously. We analyze the terminologies and trends in scientific publications and ask whether these developments serve science and society. While usage can be answered quantitatively, the authors reason from the literature studied that these developments serve to educate the masses and may help to democratize geographic information by extending the producer
\end{abstract}


base. We believe that we can contribute to a better distinction between software centered terms and the generic concept as such. The power of the visual, coupled with the potential of spatial analysis and modeling for public and private purposes raises new issues of reliability, standards, privacy and best practice. This is increasingly addressed in scientific literature but the required body of knowledge is still in its infancy.

Keywords: virtual globes; digital earth; GIS; geographic information; geographic information science; GIScience; google earth; neogeography

\section{Introduction: GIS and GIScience}

Geographic Information Systems (GIS) are technically mature and their exploitation is widespread [1]. Scholten et al. [2] recently described the explosive growth of geospatial technologies and their pervasive spread throughout the sciences and more recently also finding their way into the humanities [3]. Today GIS has found use in almost every discipline of human knowledge. In psychology, physics, environmental management, urban planning or conflict management, people are increasingly using GIS applications to address the everyday challenges of the social and biophysical world. GIS has migrated from specialized information systems into mainstream Information Technology (IT) and in doing so has not only increased the scientific understanding of space and time but also created a veritable "GISociety" [4]. This transformation has also been described as re-conceptualizing GIS as a form of media. It can be expressed as a shift of perspective-from viewing GIS as an instrument for problem-solving to viewing it as media for communication [5]. In a previous German language review article, Blaschke described the changing role of GIS from a tool to its fundamental role within GIScience [6]. In this paper, an international group of authors spanning three continents elaborate some of these earlier findings, incorporated into a GISociety perspective and reflect on recent developments of GI in mass media and specifically (freely available) GI browsers or Virtual Globes such as Google Earth, Bing Maps 3D (formerly Microsoft Virtual Earth), NASA World Wind and ArcGIS Explorer. By exploring the importance of this topic, this article will discuss the significance of these developments and their potential consequences to science and society.

Communicating geographic information via the Internet and enabling users to work interactively with geographic information requires a certain level of understanding of basic mapping principlesignorance of which opens the way for misuse and misinterpretation. Virtual Globes are powerful visualization and geo-communication tools which have reached hundreds of millions of desktops worldwide. Millions of non-expert users are empowered to not only consume but also to publish geo-information. This so called "Volunteered Geographic Information” (VGI), [7,8] creates some resulting challenges for GIScience and for the society. Sui even speaks of a "wikification of GIS" [9]. It is important to note that geography is about understanding processes in space and time which create facts and footprints in our spatial reality. These developments not only dramatically change the technology and its applications, but also raise a series of new basic GIScience questions [10], which at the same time revitalizes some older geographic questions [11,12]. GIScience increasingly deals with the effects of the changes from traditional one-way cartographic communication to a system consisting 
of millions of volunteer contributors. This voluntarism certainly has the potential to relocate and redistribute productive activities from mapping agencies to networks of non-state volunteer actors. However, if we are to design strategies and systems to maximize the advantages and minimize the risks associated with these changes, we must have a clear understanding of the people and technologies involved [13].

GIScience can be defined as that branch of information science that deals with places on or near the surface of the Earth; or alternatively as the set of fundamental principles underlying the design, testing, and use of geographic information technologies [14]. Goodchild uses the intuitive explanation that GIScience is the storehouse of knowledge that is implemented in GIS and that makes GIS possible [12]. We can summarize the communalities in the various attempts to distinguish between geographic information "systems" and "science": The first refers to the study of questions that arise from the use of tools, while GI"Science" refers to the use of a scientific approach to study the fundamental issues arising from the creation, handling, storage, and use of geographic information.

\section{Virtual Globes}

\subsection{Technical Developments and Standards}

The recent advent of freely available Virtual Globes such as Google Earth, Microsoft Bing Maps 3D and similar applications allow users to interact with and query overhead imagery and spatial data via a three-dimensional representation of the Earth [15]. Virtual Globes make it relatively straightforward to build spatially enabled web applications. It is simple to overlay available data layers and to visualize them [16]. Anybody can explore the high resolution imagery provided, and can superimpose additional layers such as street networks, place-names, hotel information or landmarks.

Keyhole was the first company to release such an Earth-viewer in 2001 and NASA's World Wind followed in 2003. They received recognition, in what is a relatively small community of interest, for virtual globes. In October 2004, Google acquired Keyhole Corporation and released Google Earth in June 2005 (Figure 1). For non-expert users, Google is associated with the notion of having created an appealing 3D browser with a "video game-like" feeling. It is widely used and implemented by a growing variety of vendors. In June 2006, Google claimed 100 million product activations worldwide and within a year (by September 2006), about 30000 copies of their programming interface (API) were in use worldwide leading to an unprecedented number of applications [16,17]. With KML (Keyhole Markup Language), Google created a de facto standard. Such a pseudo-standard is not new. There are many examples (such as VHS, ESRI's shapefile, Adobe PDF, and so forth) where a format became standard despite the fact that it was not technically superior to its competitors. For some years, there had been friction within the standardization community, but in 2008 KML Version 2.2 was adopted as an OGC (Open Geospatial Consortium) implementation standard [18].

The OGC is an international voluntary consensus standards organization. Commercial, governmental, non-profit and research organizations worldwide collaborate in an open consensus process that encourages the development and implementation of standards for geospatial content and services, GIS data processing and data exchange [19]. OGC has produced specifications, for example, the Web Feature Service (WFS) and the Web Map Service (WMS). In regard to the intrinsic question if "the 
Geographical” [11] is becoming more important, we may claim that it will only be through the development and use of advanced open systems standards and techniques for geo-processing that such success can become possible.

Figure 1. Selection of major, freely accessible Virtual Globe software and their first occurrence.

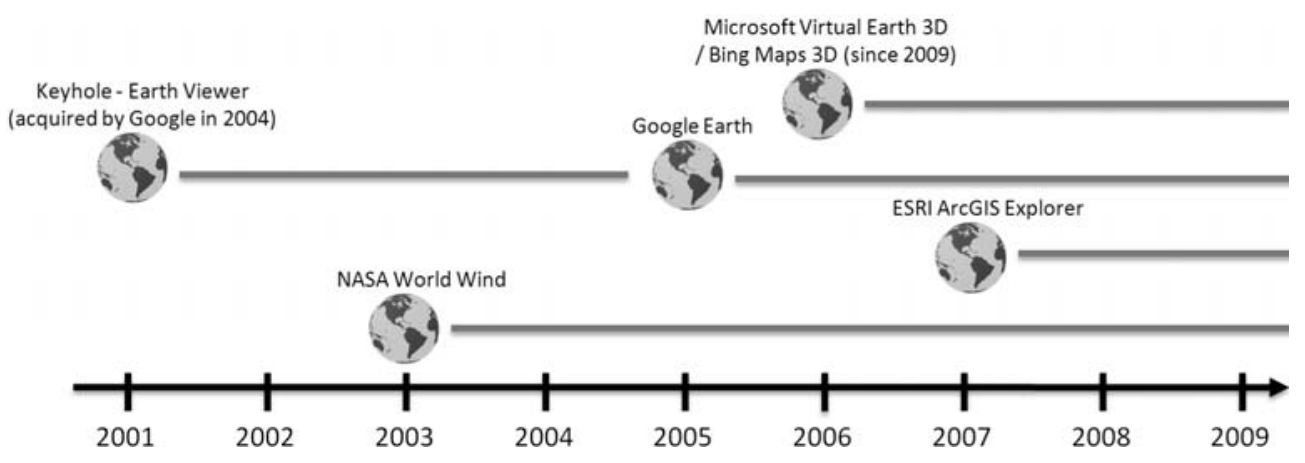

\subsection{Booming Applications}

The value of scientific data increases when we can link it to the information that a user already considers important: "scientists should take this opportunity to use GIS to present their scientific results in a way that users can easily tie to other data sources" (Butler, 2006). Online mapping services have only existed since the late 1990s. They are mainly associated with the questions "where is $x$ ?" and "how do I get there?” However, recently, online map services have become much more complex and interconnected. While 2D street maps were quickly adopted by average internet users, Virtual Globes are attracting additional attention through the use of a three-dimensional representation of the Earth. Interaction with digital information is becoming much less abstract. Working directly with spatial views (Google and Microsoft currently leading the way) ties the "online domain” directly into daily individual experiences and perceptions. New consumer demand will probably turn out to be a major driver in the development of future spatial data infrastructure services [4,20].

Another aspect is creativity and imagination. The strength of professional GIS lies in the potential for spatial analysis. It is also used for visualization and for displaying different scenarios, but it is rarely used for "playing around”. By integrating tools to encourage creative imagination, we may be able to ask more innovative and socially relevant questions about the changing character of the earth's surface, especially under conditions of global environmental change. Massification and the wider use of GIS is bound to potentially lead to an increasing number of applications which may not always obey standard cartographic rules such as maps which give wrong associations due to flawed color or symbol representations based on questionable data or presumptions. Since GIS exists as a tight coupling of spatial data, analysis, and visualization technology, such intelligent software may create incorrect conceptual models of each of these components [21]. But, we should question whether the number of inappropriate uses is significant when compared to the impact of the 500+ million unique downloads of Google Earth worldwide [22], and the increasing number of geo-services that are being offered online and via mobile services. 


\subsection{The Vision of "Digital Earth"}

The mental picture of Digital Earth, put forward by the former US Vice-President Al Gore thirteen years ago, is today appreciated as a visionary concept for many of the developments in the fields of information technology, data infrastructures, and earth observation that have taken place since then [18]. For a more complete history of Digital Earth we refer readers to Grossner et al. [23] and Elmes et al. [24]. With respect to Digital Earth, Butler noted that Google Earth has no analytic functions and is not designed to replace professional GIS software [15]. But within less than two years, GIS software companies found ways to combine easy to use Virtual Globes with their traditional analytic strengths, introducing the integration of so called "geoprocessing services". A first freely available product in this direction was ESRI's ArcGIS Explorer launched in early 2007. In contrast to ESRI’s ArcGlobe application, launched in 2004 and part of the commercial 3D Analyst extension which allows more or less analytic functions of a professional GIS, ArcGIS Explorer was the first freely available Virtual Globe from a GIS software company [25]. Goodchild did not diagnose this as competition between GIS and Google Earth rather it offered the potential to extend spatial science to a much larger community [26]. Today, via the major standards associations the vision has developed into tangible global, national and regional geo-portals. The Digital Earth Reference Model (DERM) was coined to allow for the creation of an interoperable, all encompassing, geospatial platform for information flow. DERM thus seeks to facilitate and promote the use of georeferenced information from multiple sources over the Internet.

Craglia et al. identified several challenges to the research community to achieve the vision of a next-generation "Digital Earth" [16]. These key research questions have to be seen in the context of a re-evaluation of the new technical developments that have taken place since the first vision more than 10 years ago, comprising: (i) Information integration not only of multi-source and heterogeneous information, but also multidisciplinary, multi-temporal, multi-resolution, and multi-lingual information; (ii) Space-time analysis and modeling; (iii) Visualization of abstract concepts in space; (iv) Computational infrastructures to implement scenarios; and (v) Trust, reputation and quality models for contributed information and services.

\section{4. “Doing Geography” with Virtual Globes}

Geography has changed over time. At one time, geographic discovery meant charting new territory in a literal sense [27]. The map evolved as the primary method for storing and communicating knowledge of the earth's surface. Maps serve as repositories of both the raw data and the results of geographic inquiry and mapmaking has always figured prominently in the skill set of geographers. Maps are thus indispensable tools in the geographers' search for understanding how human and physical processes act and interact on the earth's surface and the way the world works [12].

While the transition to digital mapping has taken only a few decades — with a period of time when both manual and digital techniques operated in parallel-there may be a much faster transition from the one-way communication of spatial data into a two-way, interactive geo-data publishing process. Cartography, Geography and Geoinformatics students today have to deal with Spatial Data Infrastructure (SDI) architectures, OGC standards, or the Sensor Web Enablement Initiative (SWE) in the quest for an interoperable display of real-time measurements. 
With the advent of Virtual Globes, the potential for making GIS functionality available to general users is dramatic: GIS as a term or abbreviation, respectively, may disappear. The range of GIS functionality - either explicit in GIS software or as services embedded in Virtual Globes—will expand. Wright et al. explored several meanings of “doing GIS” [28]. They categorized three levels of "doing GIS” which are condensed here and listed in reverse order:

(i) The science of GIS, concerning the analysis of the fundamental issues raised by the use of GIS.

(ii) GIS as tool making, involving the advancement of the tool's capability and ease of use.

(iii) GIS as a tool, involving the use of a particular class of software, associated hardware tools, and digital geographic data in order to advance some specific purpose.

Figure 2 illustrates the growing demand for GIScience. Through the increase of certain user groups, such as moving from the only group of geodata creator and user towards many types in the present state, the fear that popular usage of GIScience may increase flawed analyses, misleading maps and potential misuses is real [15], but such use also makes the GISociety possible [29]. Goodchild contends that GIS is inevitably linked to the study of form-how the world looks, rather than how the world works [14]. The strength of GIS will continue to be its analytical capabilities it offers for geographers to explore information. Wright et al. made the case that GIS must focus on the process of discovery and the understanding of problems [28].

Figure 2. Virtual Globes extend the user base of spatial information by enabling the masses to publish own geo-data.

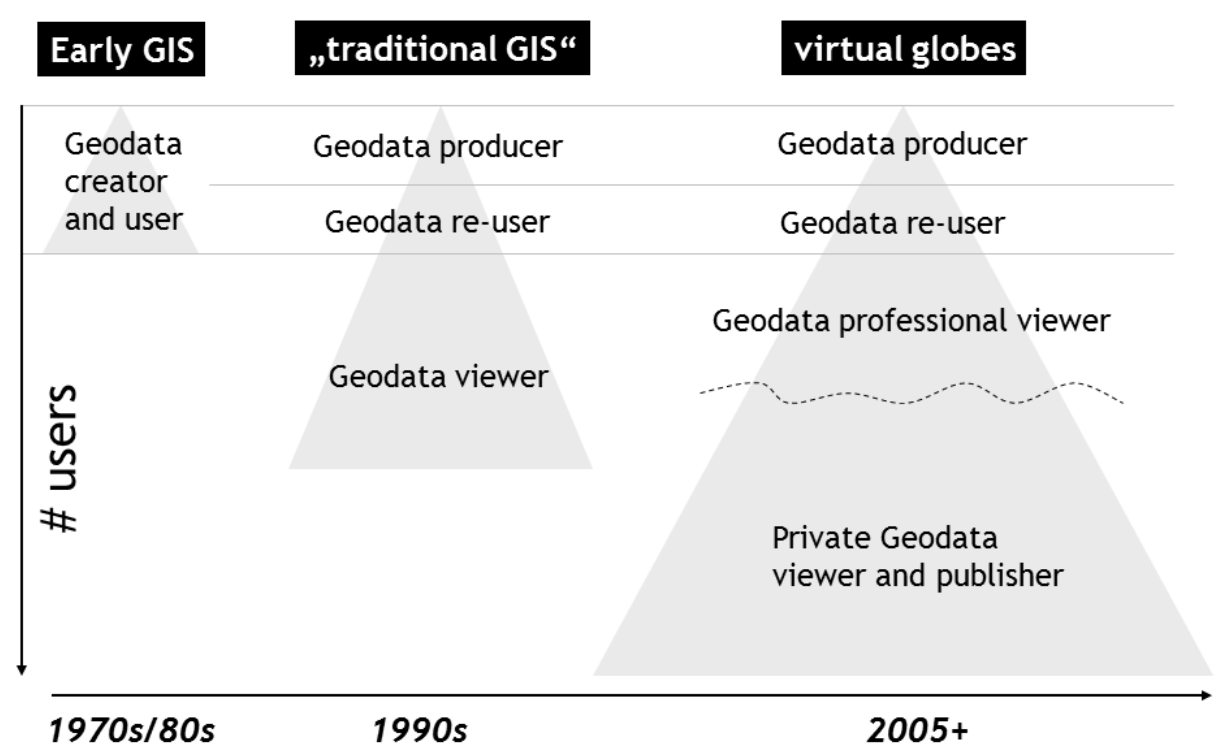

Virtual Globes in the hands of the amateur are not bound by cartographic conventions and the tyranny of pre-defined map features. According to Turner [30], they mark the end of an era of the "hegemony of GIS". Harris et al. [31] conclude that these developments-which they summarize under 'Geospatial Web'-more closely meet the spatial information needs of the humanities. Virtual Globes may provide new opportunities for geographical problem-solving, incorporating the micro-geographies of individuals and the near-real-time spatio-temporal analysis of social systems. 


\subsection{Socializing Virtual Globes}

Virtual Globes or other web-based mapping tools enable anyone with access to a computer and to the internet to create a map. They do not require cartographic skills. This raises various challenges with which GIScience must deal. For the most part, laymen are predominantly not aware of the fact that the information they get on the screen — street maps, landmarks, 3D buildings—are models of the reality and contain various types of generalization. Some of these are more obvious than others. For example, high resolution satellite data (typically one-meter resolution in urbanized areas) are construed as "the reality" and not as snapshots in time under specific spectral, temporal and spatial conditions. GIS experts are supposed to be aware of these limitations. Moreover, they presumably have skills to transform, emphasize, eliminate, summarize, exaggerate, and enlarge entities in geographic representations and to obey scaling rules [32,33]. However, Virtual Globes allow any reasonably computer-literate person to make a map or other geographic representation regardless of his/her understanding of spatial concepts. Barrotta et al. [34] argue that Virtual Globes not only make online digital cartography a reality but also use their "hackable advantages" to increase public access to geographic data. However, with more players involved, such as Microsoft, Yahoo, and others, standards, meta-information and liabilities for geoinformation become increasingly critical, especially when personal, organizational, and societal information is interlinked.

Privacy issues have been addressed in scientific research since the late 1980s and the principles for privacy protection for GIS users, as defined by Onsrud et al. [35], are fully valid (and will be discussed in more depth later in this paper). An unprecedented volume of detailed information is now at the fingertips of millions of lay users. The purpose of ensuring "geoprivacy" is to prevent individuals from being identified through locational information. "It is personal attribute information extracted from aerial imagery that may infringe upon a citizen's privacy rather than the imagery itself” [35] reads like it had been recently written. A common understanding of geoprivacy is that 'geographic data' becomes "personal data" when it is related to an identified or identifiable person. Currently, the two major areas of concern are high resolution imagery including street-level images and geo-information about citizens within the context of Location Based Services (LBS) [36].

The ease with which geographic information can be published by anybody may mislead novice users to consider themselves experts in geography or GIS. In order to confront these harmful developments, Obermeyer and Pinto [37] called for "substantive expertise in the field where GIS is to be used"; "knowledge of GIS techniques"; and the "understanding of geographic and cartographic principles, at least in rudimentary form” so as to guard against a lull and a misuse of GIS technology. Again, substantive expertise in cartography and knowledge about scales and representation cannot be expected of all the estimated hundreds of millions of users. Next to an educational mandate, the challenge is therefore to bring together industry and API programmers in order to set rules, guide users, develop and ensure standards and ground geographic information ontologically, to list some major future tasks. Obermeyer [33] reflects on the maturation of GIS into its current status as a true profession and develops a code of ethics predicting that it will be important to uphold certain professional ideals.

Current advances in GIS and GIScience favor the use of automated, digital, and online possibilities to represent geography. Furthermore, the gap between automated, digital, and online versus manual, 
non-digital, and stand-alone systems is often reflected as the North-South GIS technological divide. There are (few) claims that GIS and GIScience alienate indigenous peoples and minorities in various non-democratic countries [38] whereas the majority of recent scientific literature believes in the prevailing positive effects for developing countries or for marginalized groups [2,31,39,40]. More obvious to the mass of users is the subject of credibility. Similar to grass-root developments such as Wikipedia, users need to know that information is trustworthy. The idea that millions of private users, grass-root organizations, interest groups and businesses could publish geographic information on Virtual Globes is fascinating. However, this enthusiasm should not be dampened by a lack of watchdog organizations that should take responsibility for quality assurance and related tasks of geographic information published on Virtual Globes.

\subsection{Widening the User Base-Democratizing GIS?}

GIS-based representations of geography have already revolutionized the way people and organizations work with geography [41]. The use of GIS in other disciplines has meant that a version of geography is constantly being "exported” to other subjects, professions and the state [42] where GIS technology has gained hold. GIS has influenced visualization as the geographic representation for purposes of discovery and the study of maps as tools in scientific study. GIS has also resolved issues of representation such as speed, storage, physical deterioration, and the ease of transformation, processing and analysis. GIS can now transmit digital representations at the speed of light and store them at high density, besides the tremendous ability to transform, process, and analyze such data [1]. GIS has therefore increased the simplicity with which geography is presented but has earned critique for the same from a (comparatively small) group of scientists [38,43-47].

The use of interactive, internet-based GIS can augment the democratic decision-making process by greater citizen involvement in development issues [48]. For example, continents like Africa can look to Internet-based GIS for solutions to a myriad of problems: crime [49]; health problems such as HIV Aids; poverty and livelihood vulnerability [50], among many others. This recognition has, since the mid-1990s led to a development referred to as Public Participation GIS or PPGIS [48]. GIS via the Internet is said to be a powerful, interactive, communicational tool between different interest groups. Various studies demonstrate that it is possible to use PPGIS to involve the public in the development planning process from its very beginning. PPGIS can then be used to facilitate the delivery of spatial information to participants and allow them to return their information for inclusion in the database. Although this potential is described in scientific literature and a significant PPGIS community has evolved [51] the number of fully productive online applications remains surprisingly small [52] even though we can develop and apply region-, sector-, and community-specific PPGIS to identify and confront development problems through consultative and participatory approaches.

\subsection{Heterogeneous Terminology: An Empirical Study}

Typical for a new trend (to avoid the term paradigm) is the lack of a widely accepted terminology and its low impact in established scientific journals [53]. Most common terms which are used in scientific literature include "Virtual Globes”, "Virtual Earth”, "Digital Earth”, “Digital Globes”, "Geobrowsers" (with or without hyphen)—next to the software specific terms such as "Google Earth". 
In most cases terms incorporating the word "Earth" are used in singular form while most others are predominantly used as plural. Harvey [54] suggests the use of the term "Digital Earths" in plural form due to underlying scientific, administrative, cultural and political questions germane to proposed and existing Digital Earth activities. Harvey also underpins that thinking about these terms when we use them is part of reflecting on what our work involves and the aspects we wish to emphasize. Schultz et al. [39] argue that Virtual Globes are so named because of their approach visualizing the Earth as a three-dimensional globe that one can "fly" above. As Schultz et al. [39] stated, Virtual Globes software and their applications are changing so rapidly that some of the information may have changed by the time it is published in this article. Some authors refer to the development of virtual maps on the Internet as the Geoweb or Geospatial Web [31,40,55-57]. Others employ the term "Geoportal" especially when referring to them as Web gateways that organize content and services related to geographic information being part of Spatial Data Infrastructures [20,58].

We therefore undertook an analysis of the use of terminology in scientific literature. We analyzed the use of generic terms "Virtual Globes" and "Digital Globe" as well as the software specific terms “Google Earth” and "Virtual Earth” for the years 2005 to 2010. All searches were restricted to title, abstract and keywords. Table 1 illustrates that the resulting figures are relatively low. For instance, for this period the term "Virtual Globe" appeared 56 times in ISI. For comparison, the same search was performed for the term "geography" and revealed approximately 6300 entries for the same period. The topic, therefore, is not yet very prominent in scientific journal articles.

Table 1. Number of citations for the key terms used in this article.

(a) Total number of publications.

\begin{tabular}{|c|c|c|c|c|c|c|c|c|}
\hline \multirow[b]{2}{*}{$\begin{array}{c}\text { Publication } \\
\text { Year }\end{array}$} & \multicolumn{4}{|c|}{ ISI Web of Science } & \multicolumn{4}{|c|}{ Google Scholar } \\
\hline & $\begin{array}{c}\text { Google } \\
\text { earth }\end{array}$ & $\begin{array}{c}\text { Virtual } \\
\text { globe }\end{array}$ & $\begin{array}{c}\text { Virtual } \\
\text { earth }\end{array}$ & $\begin{array}{c}\text { Digital } \\
\text { globe }\end{array}$ & $\begin{array}{c}\text { Google } \\
\text { earth }\end{array}$ & $\begin{array}{c}\text { Virtual } \\
\text { globe }\end{array}$ & $\begin{array}{c}\text { Virtual } \\
\text { earth }\end{array}$ & $\begin{array}{c}\text { Digital } \\
\text { globe }\end{array}$ \\
\hline 2005 & 0.6 & 3.8 & 8.7 & 15.8 & 0.8 & 5.3 & 13.1 & 12.7 \\
\hline 2006 & 5.7 & 5.9 & 10.1 & 11.6 & 6.9 & 7.1 & 17.2 & 33.9 \\
\hline 2007 & 17.1 & 3.0 & 13.4 & 16.6 & 13.5 & 12.5 & 17.2 & 12.7 \\
\hline 2008 & 19.9 & 7.6 & 16.1 & 22.5 & 16.8 & 16.0 & 19.2 & 8.5 \\
\hline 2009 & 21.8 & 34.4 & 19.2 & 9.2 & 24.7 & 23.1 & 9.1 & 8.5 \\
\hline 2010 & 34.9 & 45.3 & 32.6 & 24.3 & 37.3 & 35.9 & 24.2 & 23.7 \\
\hline Total & 100.0 & 100.0 & 100.0 & 100.0 & 100.0 & 100.0 & 100.0 & 100.0 \\
\hline
\end{tabular}

(b) Total publications.

\begin{tabular}{ccc}
\hline $\begin{array}{c}\text { Publication } \\
\text { Year }\end{array}$ & $\begin{array}{c}\text { ISI Web of } \\
\text { Science }\end{array}$ & Google Scholar \\
\hline 2005 & 72 & 27 \\
2006 & 95 & 94 \\
2007 & 146 & 154 \\
2008 & 186 & 188 \\
2009 & 254 & 428 \\
2010 & 396 & 606 \\
\hline Total & 1158 & 1497 \\
\hline
\end{tabular}


On the other hand, Google Scholar reveals a high number of hits for the term "Google Earth”. This might be biased by Google's online search engine algorithm. However, all in all, a clear growth trend can be observed (Figure 3) when summing all relevant terms but discussion of the topic remains at a very low level in the scientific literature. The growth of new terms (either scientific or non-scientific) prefixed with "geo" or "GI" may have variegated the search returns. These terms may be used with hyphens (-) and sometimes without and this is likely to lead to some inaccuracies in the results of published work. This suggests the need for appropriate "spatial grammar" as to this point Virtual Globes appear to be only vaguely addressed as a scientific subject of research [59].

Figure 3. Number of publications during 2005-2010. (a) Total publications as per ISI Web of Knowledge; (b) Total publications as per Google Scholar; (c) Cumulative number of publications by different keywords.

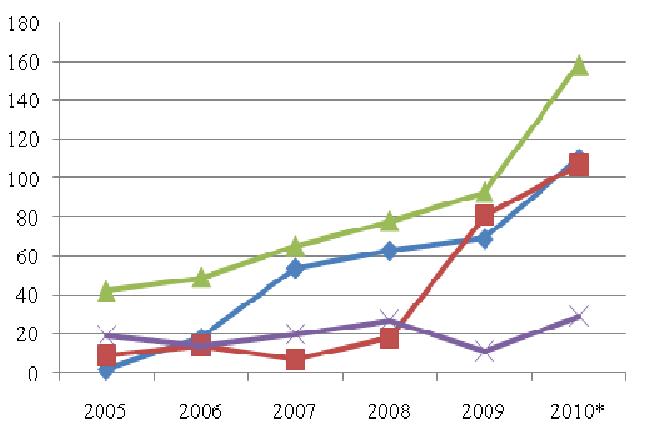

(a)

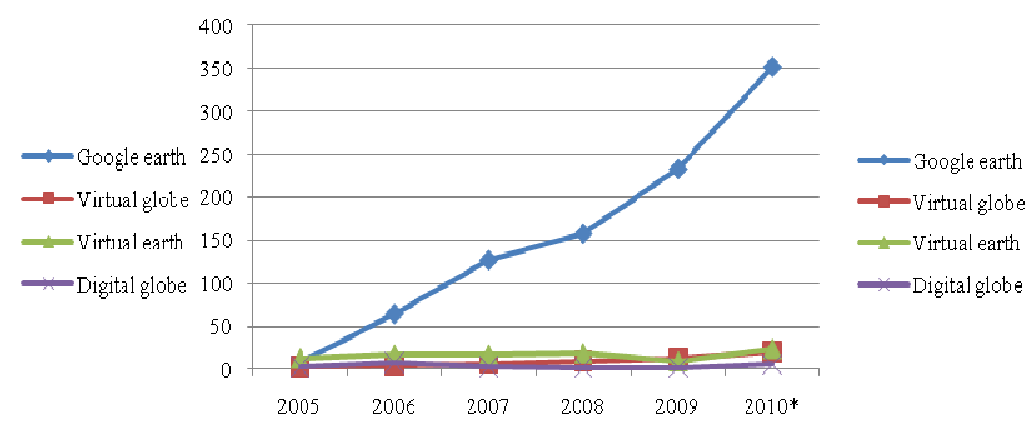

(b)

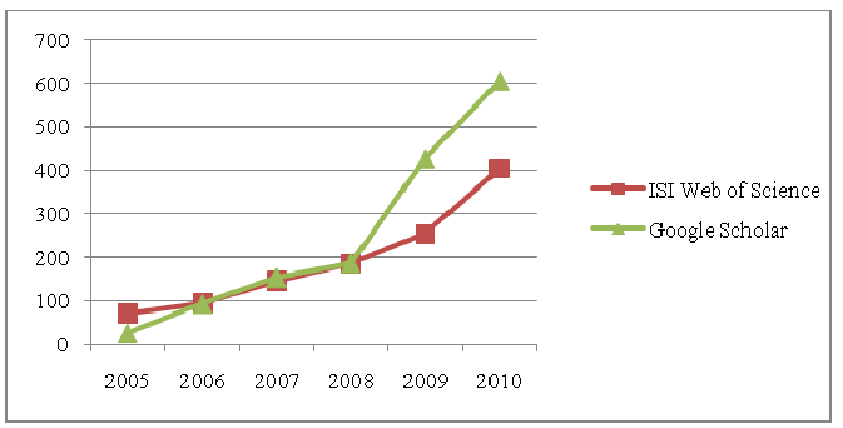

(c)

The authors are well aware of critiques and skepticism about bibliometric analysis and want to be careful with the interpretation of the resulting numbers. It is not about exact numbers. The figures and graphics should only support our argument that there was initially a tight link between software-specific terminology and the underlying concept. We may conclude that with an offset of a few years, generic terms have been used more often. There may also be a flaw: specific software terms are in tendency used in empirical studies whereas generic terms are mainly used in scientific studies about the technology and when developing general concepts and methodologies. There is much more work using Virtual Globes than scientifically studying Virtual Globes; that is to be expected and even desirable. Virtual Globes are increasingly used in studies of earth-related phenomena with geographic information and-like with the maturation of any technology — they may not be named prominently in the title or abstract. 


\section{Bias on "The Mappable"?}

\subsection{Some Critique}

GIS has been criticized for being a computer-driven tool that biases research towards the mappable or "GISable" and that many geographic models do not adequately represent geographic realities as conceptualized by potential users $[43,44,60]$. The flat, two-dimensional map of the past has morphed into the Digital Earth accessible on the web [27]. Critique holds that GIS represents yet another instrument of capital control and government surveillance [43,61]. PPGIS is considered by some $[47,48,62]$ to be subsumed into what is today sometimes called Critical GIS [63]. Critical GIS may be seen as an umbrella to encompass all research on the societal effects of GIS (e.g., geosurveillance), the social processes that should or should not be modeled by GIS (e.g., gender movement in space), or the representation, ontology, and epistemology of GIS [44,62,64]. MacEachren [65] categorizes collaborative uses of GIS using spatial and temporal dimensions, distinguishing same place and different place collaborations, and synchronous and asynchronous collaborations. In this respect Virtual Globes may be used collaboratively in any of these conditions, though commonly accessed via the Webby dispersed single lay-users (asynchronous collaboration) or used by experts in public group settings (co-located and synchronous, [66]).

Interestingly, similar to some early GIS enthusiasm an international journal allowed a certain degree of commercialism: Jones [67] states in the abstract: "the Google geospatial team wove long-standing wisdom, fresh technical thinking, and their vision of the future to create a global information landscape where people experience a uniquely real understanding of the answers to their questions...”. In an analogy to GIS we expect that such unscientific claims will feed further critique. Sui [68] sharply summarizes the gist of criticism to GIScience as certain aspects of reality transcend computation and thus do not lend themselves to algorithmic processes. Recent trends in Virtual Globes will not sweep away this critique but may shift the limits of the "mappable”. Within the short lifespan of these Virtual Globes we have seen new applications arising which "map the unmappable” for example real-time 3D animations developing into 4D spatio-temporal process illustrations [29,66]. Sheppard and Cizek [66] argue that "the Google Earth phenomenon", which features realistic imagery of places, cannot be dealt with only as a question of spatial data and geographic information science. The visualization power of Virtual Globes enables a wide range of communicating scientific and environmental information, taking it well beyond the realm of conventional spatial data and geographic information science, and engaging more complex dimensions of human perception and aesthetic preference.

\subsection{Digital Earth and Neogeography}

The success of Google Earth may be perceived as a further step towards the envisioned "Digital Earth" expressed by Al Gore in 1998 (see also [23]). It is also many-fold and encompasses the high level of usability, the huge amount of freely available data (search and explore) and the open file format KML. Recently, we witnessed the rise of "day to day geography” [69] and the growing use of the term "Neogeography" [30,70]. This contrasts classic GIS tools, targeted techniques and applications with areas of approachable, colloquial applications. Neogeography may also be seen as an umbrella for a diverse set of practices that (mostly) fall outside the professional geographic domain. Its 
popularity can be credited to the ability to communicate and share data through simple, freely available tools that can be learnt quickly and effectively without immersion in professional activities [70]. Rather than making claims on scientific standards, methodologies of Neogeography tend towards the intuitive, expressive, personal, absurd, and/or artistic, but they may just be idiosyncratic applications of "real" geographic techniques. The two realms can overlap as the same problems are presented to different sets of users: experts and non-experts. In a Web2.0 environment geographic content and applications can be deployed and used with minimal consideration or knowledge of the underlying and fundamental principles of geodesy, cartography, and/or geography. This fact bears both the potential of "fresh thinking” and of misuse.

\section{Conclusions}

\subsection{Virtual Globes: Educating the Masses?}

Although small in numbers, earlier work already paid attention to how maps inscribe power and support the dominant political structures. Wood's "The Power of Maps" [71] was particularly significant in this regard. Crampton and Krygier [72] define critical cartography as a one-two punch of new mapping practices and theoretical critique. They also state that the terms critical GIS and critical cartography overlap but do not coincide. Critical GIS refers to the social implications of geographic information systems, the hardware and software for interactive spatial data visualization and analysis, while critical cartography is a broader term referring to maps, mapping and map-making more generally. How one differentiates between these terms can vary depending on one's understanding of the linkages between GIS and cartography.

Virtual Globes open access to 'GIS-like functionality' for the masses. In principle, they may enhance community participation in planning and lead to more transparency of some planning outcomes. People can virtually explore what their neighbors do in their backyards and similarly activists, grass-root organizations or simply concerned citizens may employ Virtual Globes as a means to support public participation.

For the developments discussed in this paper we essentially avoid the discussion "tool or science" $[6,45,60]$ since Virtual Globes will provide platforms for publishing scientific results, they may also be used for collaboration within research projects. Ahlqvist [44] argued that the widely spread application of GIS in Geography has meant the strengthening of positivist epistemology. He suggests that the positivist epistemology in GIS is based on the logic of advancing information technology and should thus be labeled as "technopositivism". One could reasonably speculate that the developers of Google Earth were thinking as much about epistemology as were the developers of the iPod or any mass market software game.

Through Virtual Globes, geographic information reaches the desktops of millions of Internet users. We take it for granted that maps allow users to present, synthesize, analyze and explore the real world [32], we can extrapolate that visually appealing, interactive 3D browsers-where people can virtually explore their neighborhoods or their next holiday destinations in detail-are very attractive to a large cohort of computer-literate users worldwide. 
Computer-based cartography has enabled the realization of a dream that, a few decades ago, was almost considered impossible - to create a map within a few seconds [73]. This might be of considerable concern to trained cartographers, as inappropriate and biased applications have already been reported on different websites. Still, the potential for science is enormous. "Just as the PC democratized computing, so systems like Google Earth will democratize GIS” [15]. We believe that Virtual Globes applications in practice lead to empowerment when compared with top-down applications and that this has yet to be critically examined. They may be biased towards natural science applications [74,75] but especially grassroots-organizations and commercial location based services utilize information about place and location as an essential part of their business, societal mission or research in the humanities. In fact, despite the lack of precise figures on distribution of applications we may speculate that the bias of sophisticated analytical GIS programs may be even higher than a potential bias of Virtual Earth applications. We can at least refer to recent publications $[2,3,74,76]$ and argue that the explosive growth of geospatial technologies most recently leads to a more pervasive spread throughout the sciences.

\subsection{Positioning and Privacy}

"The Geographical” [11] is almost becoming ubiquitous. We may compare it to "ubiquitous computing" or "pervasive computing". Weiser [77] described the integration and diffusion of computers into our daily lives and identified three waves in computing: The early years were characterized by mainframes (one computer, many people). The second wave was dominated by PCs (one person, one computer) and followed by ubiquitous computing (one person, many computers), which took off in the late 1980s. Ubiquitous computing integrates computation into the environment rather than having computers as distinct objects. Through technical improvements such as RFID tags, small and powerful CPUs and advancements within location based services (GPS, Mobile Communication) the relevance of pervasive computing has increased significantly. Challenges from a societal point of view can be seen within the issues of privacy, security, unmastered complexity, free speech and intellectual property [78].

Location-based services have been identified as a future growth market and geotechnology is seen, next to bio- and nano-technology as one of the three defining technologies of the 21st Century [79]. As the Internet has blurred the public-private spheres, a current skepticism of privacy mistrust can be observed. However, with new sensors, RFID tags and mobile phones, the privacy of each individual seems to become more centralized and easily observable. The case of the logistics provider United Parcels Service (UPS) in 1996 shows how sensitive this topic can be. UPS introduced GPS in its trucks to monitor their location from a central point to achieve higher fleet management efficiency, provide better service to UPS customers and gain cost savings for the company. UPS employees went on strike. Their main concern was that the system could be used to monitor employee performance, work hours, and whereabouts during the working day. Finally a solution was reached through contractual agreements and limitations to the use of GPS information [80]. Legal frameworks have since been established which protect the "location privacy" of individuals [81] (USA: several communication acts; European Union: several directives). However, this issue will be prominent in future debates and may lead to an increasing emphasis on "personal geographical space”. Torrens [82] even believes that 
developments in the precision of positioning systems and potency of contextual analysis could potentially erode location privacy for individuals in their workplaces, homes, and recreation spaces whereby he is referring to empirical findings of Dobson and Fisher [83] and Armstrong and Ruggles [84].

\subsection{Towards a GISociety}

Location and space are becoming increasingly important in the information technology revolution [70]. GIScience has started to lay the foundation to investigate and develop solutions regarding distributed, team decision-making in a location-based, computer aided environment. The increasing availability of advanced computer and GPS technologies leads to new opportunities for teams of decision-makers to collaborate and share information in dynamic, time-critical, decision-making environments. Beyond technological developments it is even more important to understand the consequences to society from legal issues (including copyright and privacy questions) to ethics, democracy, and equity. A respective body of knowledge specific to the geographic domain is just developing [29,70]. Access to cartographic and geographic data sets and GI services is a global problem: Not all members of society with an interest in or a need for accessing geospatial data are appropriately privileged. For many, access problems make it impossible to get information and to participate in the developing digital society. Gender problems, together with others concerning under-represented groups and equity issues, are ongoing topics of debate $[4,47,85]$. Recent literature starts to examine how Virtual Globes influence society, especially in the field of travelling behavior [86]. Future research thus requires both studies of social theory and science and technology [3,70,71].

Unlike GIS $[43,45,60,87]$ there is basically no debate about the acceptance or rejection of Virtual Globes as a method or technology. Rather, the issue revolves around a series of open questions about how such technology will be understood relative to the practices of geography, how Virtual Globes will specifically influence representations of space, society, environment, and economy at the expense of other representations, and how they will finally come to represent geography itself. Schuurman [62] conducted a content analysis of GIScience papers in key journals and publications. One very broadly defined category was “GIS and society”, which constituted 49 of 792 papers (6\%) among the pre-eminent five journals for a period of 11 years. Schuurman concludes that this facet of research has so far almost completely ignored critical GIS and argues for its inclusion.

Research needs to clarify whether or not Virtual Globes can be used to support society to independently explore patterns from spatially mappable factors. Society may then be able to utilize information about the location of phenomena and any relations between them. New applications are being developed by combining social networks, such as Facebook, with the spatial relations of individuals and then behavior mapping social processes and interconnections [88,89].

In the future, Virtual Globes will be increasingly used to map spatial patterns and distributions and to indirectly locate non-measurable properties of place, human experience, social structures or any relationships that are of concern to geography. This will also include knowledge about cultural values on land and about place, which is manifest in fuzzy and emotional terms and may need advanced semantics and ontologies incorporating concepts of naïve geography. This potential, paired with the ability of any computer-literate person to publish his or her own geographic information, will have major implications for Science and society. This is not an academic debate. When millions of users 
including public authorities rely on Virtual Globes, the resulting side effects may grow far beyond the well-known examples of misled car drivers ending up in water bodies or on ski slopes. This is confirmed by a number of well-publicized examples that include the occurrence of international boundary disputes such as the recent clash between Costa Rica and Nicaragua. La Nacion, the largest newspaper in Costa Rica reported on 4 November 2010, that an error on Google Maps had caused an international conflict in Central America when Nicaraguan troops crossed the San Juan River and planted a flag on Calero Island, which had been recognized as part of Costa Rica since 1897 [90]. Google Maps had incorrectly placed the location in Nicaragua, a fact that was used by the commanding officer as the reason why the army had set up camp. The action prompted Costa Rica to send security forces to the border to repel the invasion. In this respect, we are just starting to face a new geoinformation age and a geosociety. As the title of the paper suggests, Virtual Globes may serve science and society—and maybe the military, as well.

\section{References}

1. Longley, P.A.; Godchild, M.F.; Maguire, D.J.; Rhind, D.W. Geographic Information Systems and Science, 3rd ed.; John Wiley \& Sons: Chichester, UK, 2001.

2. Scholten, H.J.; van de Velde, R.; van Manen, N. Geospatial Technology and the Role of Location in Science; Springer: Dordrecht, The Netherlands, 2009.

3. Corrigan, J. Qualitative GIS and Emergent Semantics. In The Spatial Humanities: GIS and the Future of Humanities Scholarship; Bodenhamer, D.J., Corrigan, J., Harris, T.M., Eds.; Indiana University Press: Bloomington, IN, USA, 2010.

4. Strobl, J. GI Science and technology-where next? GIS Dev. 2005, 9, 40-43.

5. Sui, D.Z.; Goodchild, M.F. A tetradic analysis of GIS and society using McLuhan's law of media. Can. Geogr. 2003, 47, 5-17.

6. Blaschke, T. Geographische informationssysteme: Vom werkzeug zur methode. Geogr. Z. 2003, 2, 95-114.

7. Goodchild, M.F. Commentary: Whither VGI? GeoJournal 2008, 72, 239-244.

8. Elwood, S. Volunteered geographic information: Future research directions motivated by critical, participatory, and feminist GIS. GeoJournal 2008, 72, 173-183.

9. Sui, D.Z. The wikification of GIS and its consequences: Or Angelina Jolie's new tattoo and the future of GIS. Comput. Environ. Urban Syst. 2008, 32, 1-5.

10. Blaschke, T.; Strobl, J. Geographic information science developments. GIS. Sci. 2010, 23, 9-15.

11. Foody, G.M. GIS: Stressing the geographical. Prog. Phys. Geogr. 2004, 28, 152-158.

12. Goodchild, M.F. The validity and usefulness of laws in geographic information science and geography. Ann. Assoc. Am. Geogr. 2004, 94, 300-303.

13. Coleman, D.J. The potential and early limitations of volunteered geographic information. Geomatica 2010, 64, 209-219.

14. Goodchild, M.F. GIScience, geography, form, and process. Ann. Assoc. Am. Geogr. 2004, 94, 709-714.

15. Butler, D. Virtual globes: The web-wide world. Nature 2006, 439, 776-778. 
16. Craglia, M.; Goodchild, M. F.; Annoni, A.; Camara, G.; Gould, M.; Kuhn, W.; Mark, D.; Masser, I.; Maguire, D.; Liang, S.; et al. Next-generation digital earth: A position paper from the vespucci initiative for the advancement of geographic information science. Int. J. Spat. Data Infrastruct. Res. 2008, 3, 146-167.

17. McLead, B. Mass-market Geo: Emerging trends and standards. Presented at the CEOS WGISS-22 conference, Annapolis, MD, USA, 12 September 2006.

18. Open Geospatial Consortium Homepage. KML (Keyhole Markup Language), Making Location Count. Available online: http://www.opengeospatial.org/standards/kml/ (accessed on 26 November 2010).

19. Open Geospatial Consortium Homepage. OGC White Paper. Interoperability and open architectures: An analysis of existing standardisation processes and procedures. Available online: http://www.opengeospatial.org/pressroom/papers (accessed on 15 July 2010).

20. Kiehle, C.; Greve, K.; Heier, C. Requirements for next generation spatial data Infrastructures-standardized web based geoprocessing and web service orchestration. Trans. GIS 2007, 11, 819-834.

21. Glennon, A. Comments on naive geography, part 2, 2006. Available online: http://geography2. blogspot.com/2006/06/comments-on-naive-geography-part-2.html (accessed on 2 December 2010).

22. News from Google-Google Homepage. Introducing Google Earth 5.0, 2009. Available online: http://www.google.com/intl/en/press/pressrel/20090202earthocean.html (accessed on 26 October 2010).

23. Grossner, K.E.; Goodchild, M.F.; Clarke, K.C. Defining a digital earth system. Trans.GIS 2008, 12, 145-160.

24. Elmes, G.; Weiner, D.; D’alessandro-Scarpari, C. Digital earth. In International Encyclopedia of Human Geography; Kitchin, R., Thrift, N., Eds.; Elsevier: Oxford, UK, 2009; pp. 198-204.

25. Kienberger, S.; Tiede, D. ArcGIS explorer review: Is this yet another virtual globe? GeoInformatics 2008, 11, 42-47.

26. Goodchild, M.F. What does Google Earth mean for the spatial sciences? In Proceedings of GIS Ireland Conference, Dublin, Ireland, October 13, 2005.

27. Colwell, R. The new landscape of science: A geographic portal. Ann. Assoc. Am. Geogr. 2004, 94, 703-708.

28. Wright, D.J.; Goodchild, M.F.; Proctor, J.D. Demystifying the persistent ambiguity of GIS as “Tool” versus “Science”. Ann. Assoc. Am. Geogr. 1997, 87, 346-362.

29. Tiede, D.; Lang, S. Analytical 3D views and virtual globes—scientific results in a familiar spatial context. Int. J. Photogramm. Remote Sens. 2010, 65, 300-307.

30. Turner, A.J. Introduction to Neogeography. O’Reilly Press: Sebastopol, CA, USA, 2006.

31. Harris, T.M.; Rouse, L.J.; Bergeron, S. The geospatial semantic web, pareto GIS, and the humanities. In The Spatial Humanities: GIS and the Future of Humanities Scholarship; Bodenhamer, D.J., Corrigan, J., Harris, T.M., Eds.; Indiana University Press: Bloomington, IN, USA, 2010; pp. 124-142.

32. Kraak, J.M. Why maps matter in GIScience. Cartogr. J. 2003, 43, 82-89.

33. Obermeyer, N.J. GIS: The maturation of a profession. Cartogr. Geogr. Inf. Sci. 2007, 34, 129-132. 
34. Barrotta, G.; Cipriano, P.; Pezzi, S.; Zanella, L. Where would you go for mapping services, [NMAs] or Google Maps? Implementing "hackable” user-driven GI services within SDIs. In ESDI: From Inspiration to Implementation; Fullerton, K., Toth, K., Eds.; 12th EC and EC GIS Workshop, Innsbruck, Austria, 21-23 June 2006.

35. Onsrud, H.J.; Johnson, J.; Lopez, X. Protecting personal privacy in using geographic information systems. Photogramm. Eng. Remote Sens. 1994, 60, 1083-1095.

36. Nouwt, S. Reasonable expectations of geo-privacy? SCRIPTed 2008, 5, 375-403.

37. Obermeyer, N.J.; Pinto, J.K. Managing Geographic Information Systems. The Guildford Press: New York, NY, USA, 1994.

38. Taylor, P.J.; Johnston, R. GIS and geography. In Ground Truth; Pickles, J., Ed.; The Guilford Press: New York, NY, USA, 1995; pp. 68-87.

39. Schultz, R.B.; Kerski, J.J.; Patterson, T.C. The use of virtual globes as a spatial teaching tool with suggestions for metadata standards. J. Geogr. 2008, 107, 27-34.

40. Elwood, S. Geographic information science: New geovisualization technologies-emerging questions and linkages with GIScience research. Prog. Hum. Geogr. 2009, 33, 256-263.

41. Peter, F.; Unwin, D.J. Re-presenting geographical information systems. In Re-Presenting GIS; Peter, F., Unwin, D.J., Eds.; John Wiley \& Sons: Chichester, UK, 2005; pp. 1-17.

42. Radcliffe, S.A. National maps, digitisation and neo-liberal cartographies: Transforming nation-state practices and symbols in postcolonial Ecuador. Trans. Inst. Br. Geogr. 2009, 34, 426-444.

43. Pickles, J. Representations in an electronic age: Geography, GIS and democracy. In Ground Truth. The Social Implications of Geographic Information Systems; Pickles, J., Ed.; The Guilford Press: New York, NY, USA, 1995; pp. 1-30.

44. Ahlqvist, T. A quest for polygon landscapes, or GIS and the condition of epistemology. Fennia 2000, 178, 97-111.

45. Schuurman, N. Trouble in the Heartland: GIS and its critics in the 1990s. Prog. Hum.Geogr. 2000, 24, 569-90.

46. O’Sullivan, D. Geographic information science: Critical GIS. Prog. Hum. Geogr. 2006, 30, 783-791.

47. Pavlovskaya, M. Theorizing with GIS: A tool for critical geographies? Environ. Plan. 2006, 38, 2003-2020.

48. Sieber, R. Public participation geographic information systems: A literature review and framework. Ann. Assoc. Am. Geogr. 2006, 96, 491-507.

49. Chainey, S.; Ratcliffe, J.H. GIS and Crime Mapping. John Wiley \& Sons: Chichester, UK, 2005.

50. Healy, D.J.; Stancioff, A. Development of a Geographic Information System in Support of Poverty Reduction, No. 7113660; World Bank: Montpelier, VT, USA, 2002.

51. PPgis.net-Open Forum on Participatory Geographic Information Systems and Technologies Homepage. Available online: http://ppgis.iapad.org (accessed on 3 December 2010).

52. Steinmann, R.; Krek, A.; Blaschke, T. Can online map-based applications improve citizen participation? In E-Government: Towards Electronic Democracy; Böhlen, M., Gamper, J., Polasek, W., Eds.; Springer: Berlin, Germany, 2005; pp. 25-35.

53. Caron, C.; Roche, S.; Goyer, D.; Jaton, A. GIScience journals ranking and evaluation: An international delphi study. Trans. GIS 2008, 12, 293-321. 
54. Harvey, F. More than names—digital earth and/or virtual globes? Int. J. Spat. Data Infrastruct. Res. 2009, 4, 111-116.

55. Scharl, A. Towards the geospatial web: Media platforms for managing geotagged knowledge repositories. In The Geospatial Web: How Geobrowsers, Social Software and the Web2.0 are Shaping the Network Society; Scharl, A., Tochtermann, K., Eds.; Springer: London, UK, 2007; pp. 3-14.

56. Hakley, M.; Singelton, A.; Parker, C. Web mapping 2.0: The neogeography of the GeoWeb. Geogr. Compass 2008, 2, 2011-2039.

57. Crutcher, M.; Zook, M. Placemarks and waterlines: Racialized cyberscapes in post-Katrina Google Earth. Geoforum 2009, 40, 523-534.

58. De Longueville, B. Community-based geoportals: The next generation? Concepts and methods for the geospatial Web 2.0. Comput. Environ. Urban Syst. 2010, 34, 299-308.

59. Mayall, K.; Hall, G.B. Landscape grammar 1: Spatial grammar theory and landscape planning. Environ. Plan. B Plan. Des. 2005, 32, 895-920.

60. Pickles, J. Tool or science? GIS, technoscience and the theoretical turn. Ann. Assoc. Am. Geogr. 1997, 87, 363-372.

61. Aitken, S.C. Public participation, technological discourses and the scale of GIS. In Community Participation and Geographic Information Systems; Craig, W., Harris, T., Weiner, D., Eds.; Taylor \& Francis: London, UK, 2002; pp. 357-366.

62. Schuurman, N. Formalization matters: Critical GIScience and ontology research. Ann. Assoc. Am. Geogr. 2006, 96, 726-739.

63. Schuurman, N. Critical GIS: Theorizing an emerging discipline. Cartographica 2001, 36, 1-108.

64. Agarwal, P. Ontological considerations in GIScience. Int. J. Geogr. Inf. Sci. 2005, 19, 501-536.

65. MacEachren, A.M. Cartography and GIS: Facilitating collaboration. Prog. Hum. Geogr. 2000, 24, 445-456.

66. Sheppard, S.R.J. The ethics of Google Earth: Crossing thresholds from spatial data to landscape visualization. J. Environ. Manag. 2009, 90, 2102-2117.

67. Jones, M.T. Google’s geospatial organizing principle. IEEE Comput. Graph. Appl. 2007, 27, 8-13.

68. Sui, D.Z. Terrae incognitae and limits of computation: Whither GIScience? Comput. Environ. Urban Syst. 2001, 25, 529-533.

69. Warf, B.; Arias, S. Introduction: the reinsertion of space into the social sciences and humanities. In The Spatial Turn. Interdisciplinary Perspectives; Warf, B., Arias, S., Eds.; Routledge: Abingdon, Oxford, UK, 2009; pp. 1-10.

70. Hudson-Smith, A.; Crooks, A.; Gibin, M.; Milton, R.; Batty, M. NeoGeography and Web 2.0: Concepts, tools and applications. J. Locat. Based Serv. 2009, 3, 118-145.

71. Wood, D. The Power of Maps. The Guilford Press: New York, NY, USA, 1992.

72. Crampton, J.W.; Krygier, J. An introduction to critical cartography. ACME Int. E-J. Crit. Geogr. 2006, 4, 11-33.

73. Slocum, T.A.; Egbert, S.L. Cartographic data display. In Geographic Information Systems: The Microcomputer and Modern Cartography; Taylor, D.R.F., Ed.; Pergamon Press: Oxford, UK, 1991; pp. 167-199. 
74. Boonstra, O.W.A. No place in history-Geo-ICT and historical science. In Geospatial Technology and the Role of Location in Science; Scholten, H.J., van de Velde, R., van Manen, N., Eds.; Springer: Dordrecht, The Netherlands, 2009; pp. 87-101.

75. Goodchild, M.F.; Janelle, D.G. Toward critical spatial thinking in the social sciences and humanities. GeoJournal 2009, 75, 2-13.

76. Warf, B.; Arias, S. Introduction: the reinsertion of space into the social sciences and humanities. In The Spatial Turn. Interdisciplinary Perspectives; Warf, B., Arias, S., Eds.; Routledge: Abingdon, Oxford, UK, 2009; pp. 1-10.

77. Weiser, M. The computer for the twenty-first century. Sci. Am. 1991, 9, 94-104.

78. Hilty, L.; Behrendt, S.; Binswanger, M.; Bruinink, A.; Erdmann, L.; Fröhlich, J.; Köhler, A.; Kuster, N.; Som, C.; Würtenberger, F. The Precautionary Principle in the Information Society. Effects of Pervasive Computing on Health and Environment, TA-SWISS, TA 46e/2005; Report of the Centre for Technology Assessment (TA-SWISS): Bern, Switzerland, February 2005.

79. Gewin, V. Mapping opportunities Nature 2005, 427, 376-377.

80. Lever, J.A. Unintended consequences of the global positioning system. Syst. Eng. 2004, 7, 217-228.

81. Beresford, A.R.; Stajano, F. Location privacy in pervasive computing. Pervasive Comput. 2003, 1, 46-55.

82. Torrens, P.M. Geography and computational social science. GeoJournal 2010, 75, 133-148.

83. Dobson, J.; Fisher, P. Geoslavery. IEEE Technol. Soc. Mag. 2003, 22, 47-52.

84. Armstrong, M.P.; Ruggles, A.J. Geographic information technologies and personal privacy. Cartographica 2005, 40, 63-73.

85. Virrantaus, K.; Fairbain, D.; Kraak, M.J. ICA research agenda on geography and geographic information science. Cartographica 2009, 44, 45-55.

86. Ren, F.; Kwan, M.P. The impact of the Internet on human activity-travel patterns: Analysis of gender differences using multi-group structural equation models. J. Transp. Geogr. 2009, 17, 440-450.

87. Taylor, P.J. GKS. Polit. Sci. Q. 1999, 9, 211-212.

88. Rouse, L.J.; Bergeron, S.J.; Harris, T.M. Participating in the Geospatial Web: Collaborative mapping, social networks and participatory GIS. In The Geospatial Web. How Geobrowsers, Social Software and the Web2.0 are Shaping the Network Society; Scharl, A., Tochtermann, K., Eds.; Springer: Berlin, Germany, 2007; pp. 153-158.

89. Fischer, F. We are excited about maps - they are excited about maps! Tele Atlas feeds and makes use of neogeographers. GeoInformatics 2008, 7, 10-13.

90. McGee, M. Nicaragua Raids Costa Rica, Blames Google Maps, 2010. Available online: http://searchengineland.com/nicaragua-raids-costa-rica-blames-google-maps-54885 (accessed on 3 December 2010).

(C) 2012 by the authors; licensee MDPI, Basel, Switzerland. This article is an open access article distributed under the terms and conditions of the Creative Commons Attribution license (http://creativecommons.org/licenses/by/3.0/). 